\title{
Homogeneity of Catalytically Active Surface of Decationated Zeolite in Isomerization of o-Xylene*
}

\author{
by Hiroshige Matsumolo**, Fumiyoshi Kato***, Hideo Fulami**** and Yoshiro Morita***
}

\begin{abstract}
Summary: The catalytic activity of decationaled zeolite for isomerization of o-xylene was investigated at $340 \sim 460^{\circ} \mathrm{C}$ using a pulse method, and the homogeneity of the active surface was qualitatively confirmed from the activation energy obtained and the result of partial piosoning with ammonia.

The reaction rate sharply increased with the increase of the ion exchange level of the zeolite, of which the heat of adsorption and apparent activation energy were substantially independent. Increasing the pretreatment temperature of the zeolite above $400^{\circ} \mathrm{C}$ showed no appreciable change of the activation energy, whereas the reaciion rate decreased considerably. The catalytic activity of decationaled zeolite was reversibly poisoned by the introduction of ammonia to the reaction system. Postulating the Langmuir assumption for the effective adsorption of ammonia on the active surface, the reaction rate was proportionally reduced to the coverage by ammonia and the adsorption constant of ammonia was almost independent of the ion exchange level and of the pretreatment temperature.
\end{abstract}

\section{Introduction}

In understanding the properties of active sites of a solid catalyst, one of the difficulties lies in the heterogeneity of the surface. Synthetic zeolites have well defined crystal structures which can be regarded crystallographically as homogeneous. On this solid, however, there are three different types of exchangeable cation sites 1): those located in the hexagonal prisms (Site I), in the sodalite cages (Site II) and in the supercages (Site III). Furthermore, many studies ${ }^{2) \sim 4}$ by infrared spectroscopy have revealed that three kinds of hydroxyl groups having bands at $3,750,3,660$ and $3,550 \mathrm{~cm}^{-1}$ remain on the surface of decationated zeolite after the ammonium ions have been decomposed.

On the other hand, isomerization of $o$-xylene has been considered to be promoted by protonic acid which forms carbonium ion intermedi-

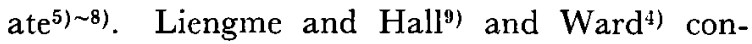
firmed, in infrared studies of chemisorption of pyridine on decationated zeolite, that only the hydroxyl group having a band at $3,660 \mathrm{~cm}^{-1}$ $\left(3,643 \mathrm{~cm}^{-1}\right.$ by Ward) functioned as a Brönsted acid. Furthermore, owing to the large size of the molecule of the reactant o-xylene, Site I seems to be excluded from the available active sites. These facts indicate that there is ample

* Received June 15, 1971.

** Chemistry Department, Memorial University.

*** Department of Applied Chemistry, School of Science and Engineering, Waseda University (Nishiokubo, Shinjuku-ku, Tokyo, Japan)

**** General Laboratory of Tokyo Gas Co., Ltd. hope for homogeneity of the catalytically active surface of decationated zeolite.

The objective of this work is to confirm the homogeneity of the active surface of decationated zeolite in $o$-xylene isomerization by means of determination of the activation energy and by systematic poisoning of the active surface with ammonia.

\section{Experimental}

\subsection{Materials}

The decationated zeolite used in this work was prepared from Linde Y Molecular Sieve (SK-40). The ammonium form was obtained by conventional ion exchange of the original sodium zeolite with $0.05 \sim 0.5 \quad N$ solution of ammonium acetate at $50^{\circ} \mathrm{C}$. The exchange levels of ammonium form, defined as the percentage of the original sodium ion replaced, were determined to be $14,25,37,44,59,67$ and 70 . These zeolites were preliminarily dricd at $110^{\circ} \mathrm{C}$, pelletized, and then ground to $48 \sim 60$ mesh particle size. X-ray diffraction revealed good crystallinity.

Prior to the examination, commercial guaranteed grade 0 -xylene was dehydrated with metallic sodium, distilled, and passed through a silica gel column. The gas chromatographic determined purity of the 0 -xylene was $100 \%$. The carrier gas used in this work was hydrogen purified by passage through a Deoxo Hydrogen Purifier. Ammonia used as a catalyst poison was a commercial cylinder ammonia without further purification. 


\subsection{Apparatus and Procedure}

The apparatus used to test the activity of the zeolite was a conventional pulse reactor coupled to a gas chromatograph (benton-34 column). The reactor itself was a pipetteshaped Pyrex glass tube of $6 \mathrm{~mm}$ diameter, and the zeolite catalyst $(0.1 \sim 0.5 \mathrm{~g})$ was held in place by a plug of clean silica wool. The reactor was positioned in an iron block to keep the reaction temperature constant within $\pm 1^{\circ} \mathrm{C}$. Prior to each measurement, fresh zeolite was treated at a desired temperature for two hours in a stream of carrier gas.

The poisoning of zeolite catalyst with ammonia was carried out at $380^{\circ} \mathrm{C}$ under a constant pressure of ammonia in order to measure the catalytic activity at equilibrium state of ammonia adsorption. The introduction of ammonia to the reaction system was done with a microfeeder described previously ${ }^{10), 11)}$.

The apparent heat of adsorption of o-xylene on zeolite was determined by conventional gas chromatographic technique ${ }^{12), 13}$.

By this method the heats of adsorption are derived from the tangent of the plot of the logarithmic retention volume against the reciprocal of the absolute temperature. To avoid confusion by the adsorption of reaction products, the adsorption measurements were carried out at low temperatures where isomerization do not take place. The weight change of decationated zeolite with thermal treatment was measured by a micro-thermobalance under similar conditions to those in the activity test.

\subsection{Expression of Catalyst Activity}

At high 0 -xylene conversion, benzene, toluene, $o-, \quad m$ - and $p$-xylenes and trimethylbenzenes were all observed in the reaction products by zeolite catalysts ${ }^{14), 15}$. Thus, three types of reactions, namely isomerization, dispropotionation and dealkylation may be considered in the acidcatalyzed reaction of $o$-xylene. This obviously complicates the expression of catalytic activity. At a lower $o$-xylene conversion, however, only $o$ - and $m$ - xylene were observed in the product. Therefore, the greater part of the activity tests in this work were carried out at temperatures below $400^{\circ} \mathrm{C}$ and at high flow velocities of carrier gas above $100 \mathrm{~m} l / \mathrm{min}$. Under these reaction conditions, the fractional conversion of o-xylene $(\mathrm{X})$ was determined by the equation

$$
\mathrm{X}=\frac{m \cdot \mathrm{X}}{o \cdot \mathrm{X}+m \cdot \overline{\mathrm{X}}}
$$

where $0-\mathrm{X}$ and $m-\mathrm{X}$ represent the mole fractions of $o$-xylene and of $m$-xylene, respectively, in the reaction product. No appreciable change

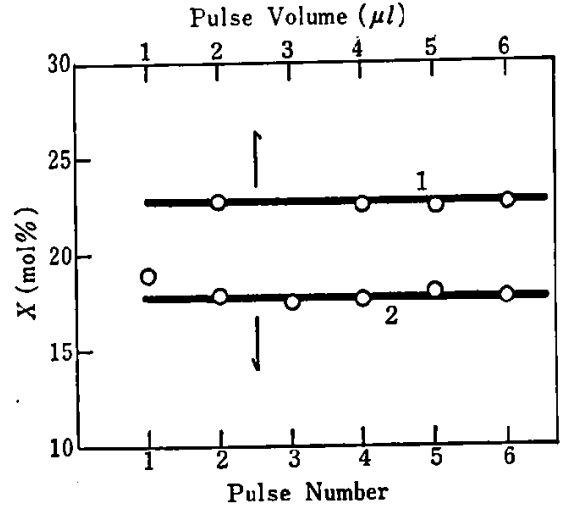

Zeolite; $67 \%$ exchanged and $500^{\circ} \mathrm{C}$ treated.

1. at $350^{\circ} \mathrm{C}, \mathrm{W} / \mathrm{F}^{\circ}=2.5 \mathrm{~g} \cdot \mathrm{min} / \mathrm{l}$.

2. at $350^{\circ} \mathrm{C}, \mathrm{W} / \mathrm{F}^{\circ}=1.7 \mathrm{~g} \cdot \min / l$.

Fig. 1 Influence of Pulse Volume and Pulse Number

in the fractional conversion was observed with change of carrier gas, such as helium, argon and nitrogen.

The fractional conversion at $350^{\circ} \mathrm{C}$ is shown in Fig. 1, as functions of the pulse frequency and of the pulse volume. This figure suggests that the activity decrease of decationated zeolite by coke formation is not very important in this pulse system, and that the conversion is substantially independent of the reactant pressure. The latter indicates the possibility of treatment by first-order kinetics. The equation for the first-order approximation

$$
k=\frac{\mathrm{F}^{\circ}}{273 R \cdot W} \ln \left(\frac{1}{1-\mathrm{X}}\right)
$$

has been used commonly in pulse reaction systems $^{16)}$. In this equation, $k, \mathrm{~F}^{\circ}, W$ and $R$ are the apparent rate constant, flow velocity of carrier gas, weight of catalyst used, and the gas

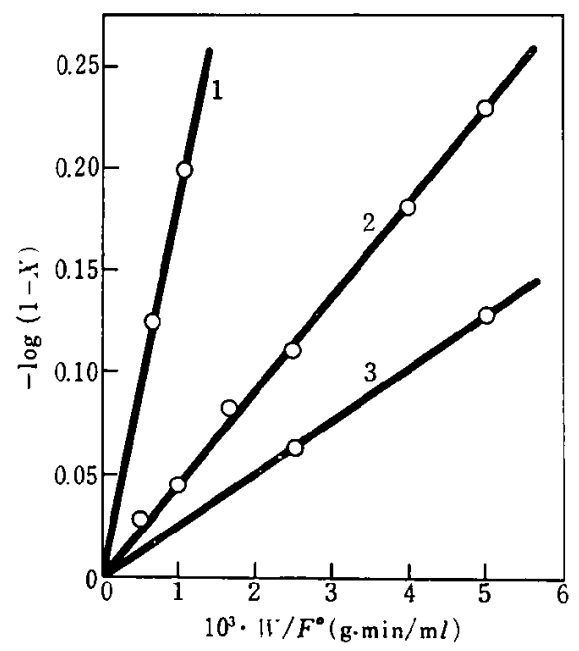

1. at $400^{\circ} \mathrm{C}$ on $67 \%$ exchanged zeolite

2. at $350^{\circ} \mathrm{C}$ on $67 \%$ exchanged zeolite

3. at $400^{\circ} \mathrm{C}$ on $25 \%$ exchanged zeolite

Fig. 2 First-order Plots of 0 -xylene Isomerization 
constant, respectively. To test the equation, the 0 -xylene conversion measured at various velocities of carrier gas, and then $-\ln (1-\mathrm{X})$ was plotted against $\mathrm{W} / \mathrm{F}^{\circ}$. From the results shown in Fig. 2, the catalytic activity of decationated zeolite for o-xylene isomerization is expressed by the apparent rate constant $(k)$ in this work.

\section{Result and Discussion}

\subsection{Effect of Ion Exchange}

The zeolite in the sodium form is completely inactive for the acid-catalyzed reaction via carbonium ion intermediate, such as isomerization of o-xylene. Conventional decationization, which is carried out by first exchanging the sodium ion with ammonium ion and subsequently decomposing the ammonium ion by thermal treatment, strongly enhances the catalytic activity of this solid. Fig. 3 shows the Arrhenius plot for a series of samples with changing the level of ion exchange. The data show linear relationships which have substantially the same slope. The values of apparent activation energy derived from these plots are listed in Table 1 along with those of the apparent heat of adsorption of the reactant o-xylene as determined by gas chromatographic technique. The former values $(24 \mathrm{kcal} / \mathrm{mol}$ ) are similar to that for the zeolite in rare earth form ${ }^{14}$ ) but rather high in comparison with the results ${ }^{17}$ ) by Hansford and Ward $(20 \mathrm{kcal} / \mathrm{mol})$. Both the activation energy and the adsorption heat were substantially independent of the ion exchange

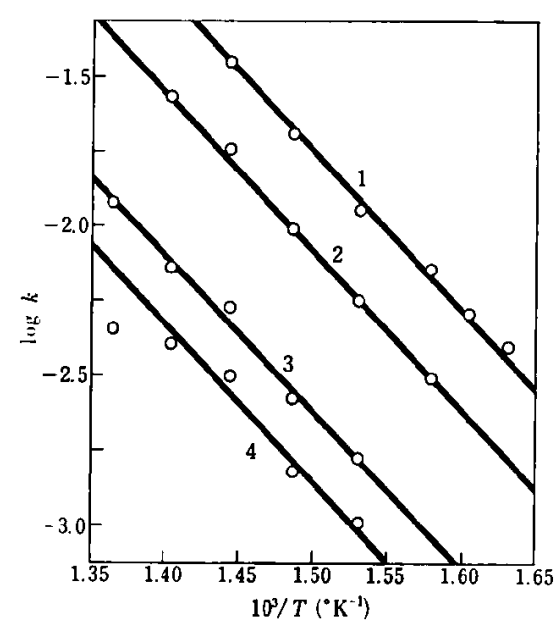

Pretreatment temperature; $500^{\circ} \mathrm{C}$ Ion exchange Icvel; $1.67 \%$

2. 44

3. 25

4. 14

Fig. 3 Arrhenius Plots Showing Activity Dependence on Ion Exchange Level of Zeolite
Table 1 The Influence of Ion-Exchange Level on Catalytic Properties of Decationated Zeolite ${ }^{\mathrm{a}}$ )

\begin{tabular}{c|c|c|c}
\hline $\begin{array}{c}\text { Na Ion } \\
\text { Replaced } \\
(\%)\end{array}$ & $\begin{array}{c}10^{2} k \text { at } 400^{\circ} \mathrm{C} \\
(\mathrm{mol} / \mathrm{g} \cdot \text { atm } \\
\mathrm{min})\end{array}$ & $\begin{array}{c}\text { Activation } \\
\text { Energy } \\
(\mathbf{k c a l} / \mathrm{mol})\end{array}$ & $\begin{array}{c}\text { Adsorption } \\
\text { Heat }{ }^{\mathrm{b})} \\
(\mathrm{kcal} / \mathrm{mol})\end{array}$ \\
\hline 13.9 & 0.149 & 24.1 & 18.3 \\
24.8 & 0.262 & 23.5 & 18.3 \\
36.9 & 0.938 & 24.1 & 18.6 \\
44.0 & 0.948 & 24.1 & 18.4 \\
59.0 & 1.81 & 24.4 & 18.0 \\
66.5 & 2.04 & 24.4 & 18.5 \\
\hline
\end{tabular}

a) Pretreated at $500^{\circ} \mathrm{C}$.

b) Measured by a gas chromatographic method in the temperature range of $250 \sim 330^{\circ} \mathrm{C}$.

level, on which the rate constant strongly depended.

Thus, the level of ion exchange does not influence the intensive factor such as activation energy and heat of adsorption, but does influence the extensive factor such as frequency factor. This may indicate that change in the number of decationated sites on the zeolite does not affect the strength of the active sites for o-xylene isomerization.

In accordance with the above consideration, a simple relationships was expected to exist between the activity of the zeolite and level of ion exchange. The actual relationships obtained was, however, somewhat complicated. The understanding of this inconsistency may be facilitated by the concept reported by Rabo et al. ${ }^{18)}$. That is, the exchanged cations $\left(\mathrm{NH}_{4}\right.$ ions in this study) are distributed between "surface sites" and "hidden sites" and only the former are available for catalysis. Thus, this com. plicity does not mean the heterogeneity of the catalytically active surface, but it may be because of the heterogeneity of ion exchange sites.

\subsection{Effect of Thermal Treatment}

Preliminary thermal treatment plays quite an important role in the catalytic properties of decationated zeolite. Fig. 4 shows the Arrhenius plots for a $67 \%$ exchanged zeolite pretreated at various temperatures. In Table 2 the apparent rate constant and the apparent activation energy are listed together with the result of thermogravimetric analysis, where the water content is expressed as an amount of volatile component (water and ammonia) of the zeolite after each calcination, assuming that the zeolite treated at $1,000^{\circ} \mathrm{C}$ contains no volatile matter. Water content and catalytic activity (the rate constant) of decationated zeolite decreased with the rise of pretreatment temperature. On the other hand, the activation energy was almost independent of the thermal treatment.

Therefore, the strength of the catalitically 


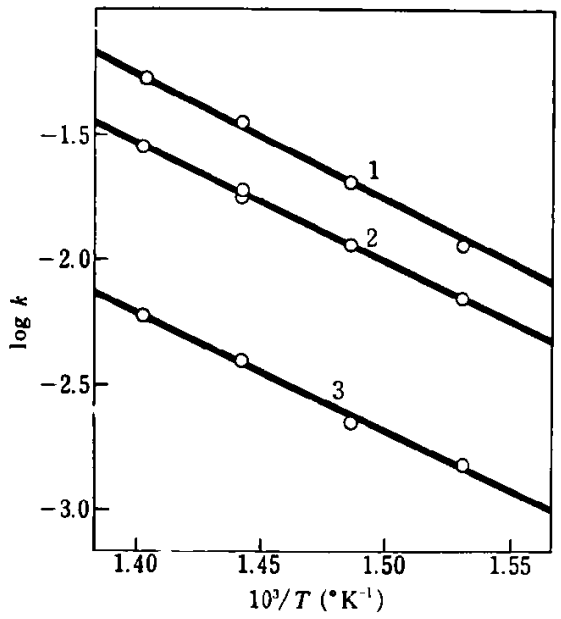

Ion exchange level; $67 \%$

Pretreatment temperature; $1.500^{\circ} \mathrm{C}$

2. 600

3. 700

Fig. 4 Arrhenius Piots Showing Activity Dependence on The:mal Treatment of Zeolite

Table 2 The Influence of Thermal Treatment on Catalytic Properties of Decationated Zeolite ${ }^{a)}$

\begin{tabular}{c|c|c|c}
\hline $\begin{array}{c}\text { Treatment } \\
\text { Temp. } \\
\left({ }^{\circ} \mathrm{C}\right)\end{array}$ & $\begin{array}{c}10^{2} k \text { at } 380^{\circ} \mathrm{C} \\
(\mathrm{mol} / \mathrm{g} \cdot \mathrm{atm} \cdot \\
\mathrm{min})\end{array}$ & $\begin{array}{c}\text { Water } \\
\text { Content } \mathrm{b}) \\
(\mathrm{mg} / \mathrm{g})\end{array}$ & $\begin{array}{c}\text { Activation } \\
\text { Energy } \\
(\mathrm{kcal} / \mathrm{mol})\end{array}$ \\
\hline 400 & 1.25 & 22.0 & - \\
500 & 1.12 & 19.9 & 24.4 \\
600 & 0.808 & 14.0 & 24.2 \\
700 & 0.153 & 8.5 & 24.2 \\
\hline
\end{tabular}

a) Replaced $66.5 \%$ of sodium ion.

b) Assuming that the zeolite treated at $1,000^{\circ} \mathrm{C}$ contains no volatile matter.

active sites dose not appear to be affected by the thermal treatment which may govern the number of the sites. This suggests that the catalytically active surface of decationated zeolite may be regarded as homogeneous for the isomerization of 0 -xylene.

Following Hall et al. $\left.{ }^{2}, 9\right)$, the decationation of ammonium zeolite with thermal treatment consists of the decomposition of ammonium ion to produce hydroxyl group, and removal of the proton as water to generate tricoordinated aluminium atoms. In the interaction with organic bases, the former act as the Brönsted acid and the latter as the Lewis acid. Most investigators 4),19) agree with this scheme. Effluent gas analysis of the thermogravimetric examination showed that deamination in a stream of hydrogen was almost complete at treatment below $400^{\circ} \mathrm{C}$. Therefore, the decrease in catalytic activity of the zeolite with the rise of pretreatment temperature (Table 2) is presumably due to the decrease in the number of protons available for the catalysis. This consideration is consistent with previous reports that the mi- gration of alkyl group along the aromatic ring is promoted by protonic acid ${ }^{6), 7)}$.

\subsection{Poisoning with Ammonia}

The confirmation of homogeneity of the active surface by the activation energy, as described above, seems to be charged with a certain danger in the pulse system. That is, the activity test by the pulse method will measure only a small portion of the surface sites on catalyst, since the coverage by the reactant is generally considered to be very small. Therefore, partial poisoning of decationated zeolite with ammonia was carried out to confirm the identity of the active site strength at appreciable coverage by ammonia.

The catalytic activity of decationated zeolite was considerably reduced by introduction of ammonia to the reaction system. This feature is shown in Fig. 5. A $67 \%$ exchanged zeolite, pretreated at $400^{\circ} \mathrm{C}$, was brought to $380^{\circ} \mathrm{C}$ in a stream of hydrogen $(25 \mathrm{ml} / \mathrm{g} \cdot \mathrm{min})$ and then a pulse of 0 -xylene was injected onto the catalyst. During this period $55 \%$ conversion was observed. On the introduction of $7.8 \mathrm{mmHg}$ of ammonia to the system, the conversion dropped sharply to a level of $36 \%$. When the carrier gas was returned to pure hydrogen, the original level of conversion was regained within a few minutes. Furthermore, on reintroduction of $7.8 \mathrm{mmHg}$ of ammonia, the conversion fell again to the previous level. When the ammonia pressure was increased to $38.3 \mathrm{mmHg}$, the conversion fell to $17 \%$. Thus, the poisoning of decationated zeolite with ammonia was completely reversible, and the establishment of equilibrium was expected between the ammonia in the gas phase and that adsorbed on the active surface of decationated zeolite.

Uytterhoeven et al. ${ }^{2)}$ observed in the infrared

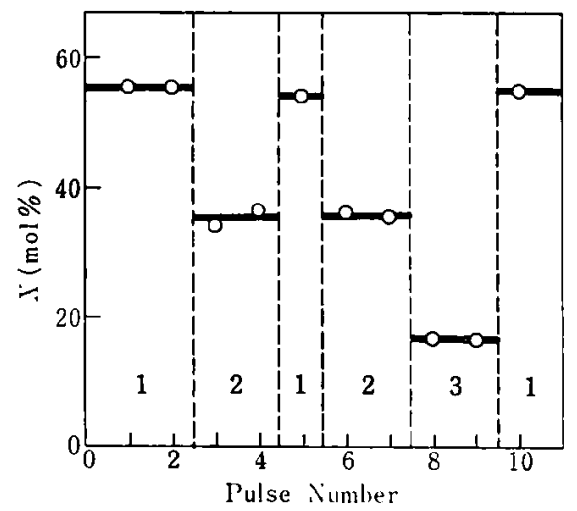

Zeolite; $67 \%$ exchanged and treated at $400^{\circ} \mathrm{C}$ Ammonia pressure; $1.0 \mathrm{mmHg}$

2. 7.8

3. 38.3

Fig. 5 Reversible Poisoning of Decationated Zeolite with Ammonia 
study that $\mathrm{NH}_{4}$ ion was generated when the zeolite in protonic form was contacted with gaseous ammonia, i.e. that the adsorption of ammonia on the protonic site was reversible, as pictured by

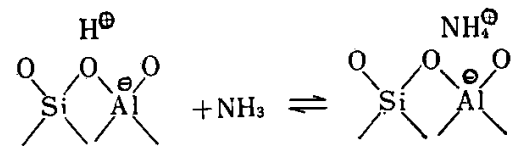

They also reported that this process was not completely reversible when the zeolite had been partially dehydroxylated, i.e. that ammonia was irreversibly chemisorbed on tricoordinated aluminum site (Lewis acid site) to form the Lewis-bound $\mathrm{NH}_{3}$. Also from this point of view, the site active for o-xylene isomerization is considered to be the Brönsted acid (presumably, a hydroxyl group having a band at $3,660 \mathrm{~cm}^{-1}$ ).

Here, we postulate that the decrease in the activity of decationated zeolite depends in first order on the amount of ammonia adsorbed on the active surface. Thus, the apparent rate constant in the presence of ammonia, $k_{\mathrm{NH}_{3}}$, will be expressed by the equation

$$
k_{\mathrm{NH}_{3}}=k_{0}\left(1-\theta_{\mathrm{NH}_{3}}\right)
$$

where $k_{0}$ stands for the apparent rate constant in the absence of ammonia, and $\theta_{\mathrm{NH}_{3}}$ is the fraction of the active surface occupied by ammonia. $\theta_{\mathrm{NH}_{3}}$ is, however, difficult to determine. The poisoning effect of ammonia may be expressed as a function of the ammonia pressure in the system $\left(P_{\mathrm{NH}_{3}}\right)$, postulating the establishment of the Langmuir assumption for the effective adsorption of ammonia on the active surface. Thus, the ratio of these constants, $k_{0} / k_{\mathrm{NH}_{3}}$, can be evaluated by the simple relation

$$
k_{0} / k_{\mathrm{NH}_{3}}=1+K_{\mathrm{NH}_{3}} \cdot P_{\mathrm{NH}_{3}}
$$

where $K_{\mathrm{NH}_{3}}$ represents the constant of ammonia adsorption effective for the catalysis.

In accordance with this equation, plots of $k_{0} / k_{\mathrm{NH}_{3}}$ against $P_{\mathrm{NH}_{3}}$ should be linear. Such plots for some decationated zeolite, which were exchanged at various levels and pretreated at various temperatures, have been obtained and shown in Fig. 6. The data obviously satisfy the above equation. Furthermore, all of the plots for various samples overlap along the same line. The slope of the plots gives the adsorption constant of ammonia on the surface active for $o$-xylene isomerization. The overlap of data taken at different concentration of active protonic sites, which are controlled by the ion exchange level and by the pretreatment temperature, suggests that the active surface of decationated zeolite ought to have the same strength level at any

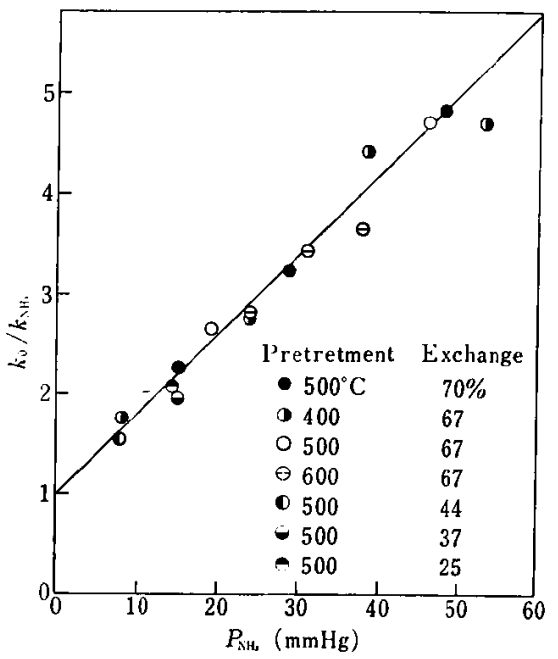

Fig. 6 Dependence of Poisoning on Ammonia Pressure

coverage. That is, it is quite natural to consider that the strength of the catalytically active sites of decationated zeolite is approximately independent of the ion exchange level and of pretreatment temperature, while the number of the sites strongly depends on both of them. These results will support the homogeneity of the catalytically active surface of decationated zeolite.

\section{References}

1) Breck, D. W., J. Chem. Educ., 41, 678 (1964).

2) Uytterhoeven, J. B., Christner, J. B., Hall, W. K., J. Phys. Chem., 69, 2117 (1965).

3) Angell, C. L., Schaffer, P. C., J. Phys. Chem., 69, 3463 (1965).

4) Ward, J. W., J. Catalysis, 9, 225 (1967).

5) McCaulay, D. A., Lien, A. P., J. Am. Chem. Soc., 74, 6246 (1952).

6) Brown, H. C., Jungh, H., J. Am. Chem. Soc., 77, 5579 (1955).

7) Matsumoto, H., Take, J., Yoneda, Y., J. Catalysis, 11, 211 (1968).

8) Matsumoto, H., Morita, Y., Bull. Japan Petrol. Inst., 10, 8 (1968).

9) Liengme, B. V., Hall, W. K., Trans. Faraday Soc., 62, 3229 (1966).

10) Matsumoto, H., Yasui, K., Morita, Y., J. Catalysis, 12, 84 (1968).

11) Matsumoto, H., Tokuno, M., Futami, H., Morita, Y., Bull. Ch:m. Soc. Japan, 43, 1899 (1970).

12) Eberly, P. E., J. Phys. Chem., 65, 68 (1961); ibid.. 66, 812 (1962).

13) Habgood, H. W., in "The Solid-Gas Interface" (1967) Marcel Dekker, New York.

14) Matsumoto, H., Morita, Y., J. Chem. Soc. Japan (Ind. Ch:m. Sect.), 70, 1674 (1967).

15) Matsumoto, H., Morita, Y., ibid., 71, 1004 (1968).

16) Bassett, D. W., Habgood, H. W., J. Phys. Chsm., 64, 769 (1960).

17) Hansford, R. C., Ward, J. W., J. Catalysis, 13, 316, (1969).

18) Rabo, J. A., Angell, C. L., Kasai, P. H., Schomaker, V., Discussion Faraday Soc., 41, 328 (1966).

19) Hattori, H., Shiba, T., J. Catalysis, 12, 111 (1968). 